Advances in Developing Human Resources

Special Issue

Human Resource Development: The Birth of an Academic Discipline

Developing a Tradition of Scholarship: The Emergence and Evolution of the AHRD

Sponsored Journals

Andrea D. Ellinger

The University of Texas at Tyler

Andrea_ellinger@uttyler.edu

Carole J. Elliott

University of Roehampton

Carole.Elliott@roehampton.ac.uk

\author{
Kimberly S. McDonald \\ Indiana-Purdue University Fort Wayne \\ mcdonalk@ipfw.edu
}

Julia Storberg-Walker

George Washington University

jswalker@email.gwu.edu 


\section{Developing a Tradition of Scholarship}

\section{The Problem}

Research and theory are the lifeblood of academic disciplines along with the peer-reviewed journals that disseminate such scholarship. Journals become critical repositories that capture the histories and evolution of such disciplines, and their scholarly contributions generate new knowledge that can stimulate further research and improve practice. The Academy of Human Resource Development (AHRD) sponsors four peer-reviewed journals that have contributed to the birth and evolution of the discipline of human resource development (HRD). Yet, little is known about how they came into being, how they have evolved, and what their impact has been within the field of HRD.

\section{The Solution}

This article captures the histories of the emergence and evolution of the four refereed journals sponsored by the AHRD through the unique voices of current and recent past editors of these journals. It then considers common themes of scholarship across the four journals that have helped to shape HRD.

\section{The Stakeholders}

Students, researchers, and scholar practitioners in the field of HRD and related fields who are interested in learning more about the histories of the journals sponsored by the AHRD, along with their contributions to the scholarship in HRD will benefit from reading this article.

\section{Key Words}

AHRD Sponsored Journals, HRD, HRD journals, Scholarship 


\title{
Developing a Tradition of Scholarship
}

\section{Advances in Developing Human Resources \\ Special Issue}

\author{
Human Resource Development: The Birth of an Academic Discipline
}

\section{Developing a Tradition of Scholarship: The Emergence and Evolution of the AHRD Sponsored Journals}

\section{Introduction}

The importance of peer reviewed journals for academic disciplines has been acknowledged by many scholars, perhaps, though, most eloquently by Swanson (2009) who stated, "Research is the soul of any respected academic discipline. Research journals are the primary vehicle for displaying scholarship in a discipline. They are the single most important anchor if any discipline is to be honoured, protected, and celebrated" (p. 4). The Academy of Human Resource Development (AHRD), the "largest human resource development (HRD) research association" (Ghosh, Kim, Kim, \& Callahan, 2013, p. 302), sponsors four refereed journals: Human Resource Development Quarterly (HRDQ), Human Resource Development International (HRDI), Advances in Developing Human Resources (ADHR), and Human Resource Development Review $(H R D R)$ as presented in Table 1. Although it is important to acknowledge that there are several other highly respected journal venues for publishing human resource development research, such as the European Journal of Training and Development, the International Journal of Training and Development, and the Journal of Workplace Learning, the focus of this contribution is to chronicle the histories and contributions of the AHRD sponsored journals to the evolving field of HRD in the order of their beginnings. 


\section{Developing a Tradition of Scholarship}

Table 1. The Four Journals Sponsored by the AHRD

\begin{tabular}{|c|c|c|c|c|}
\hline Journal & Mission/Scope & $\begin{array}{c}\text { Inaugural } \\
\text { year }\end{array}$ & Current Editor & $\begin{array}{c}\text { Special } \\
\text { Features }\end{array}$ \\
\hline $\begin{array}{c}\text { Human } \\
\text { Resource } \\
\text { Developm } \\
\text { ent } \\
\text { Quarterly } \\
(\text { HRDQ) }\end{array}$ & $\begin{array}{l}\text { Human Resource Development } \\
\text { Quarterly is the first scholarly } \\
\text { journal focused directly on the } \\
\text { evolving field of human resource } \\
\text { development (HRD). It provides a } \\
\text { central focus for research on human } \\
\text { resource development issues as } \\
\text { well as the means for disseminating } \\
\text { such research. HRDQ recognizes } \\
\text { the interdisciplinary nature of the } \\
\text { HRD field and brings together } \\
\text { relevant research from the related } \\
\text { fields, such as economics, } \\
\text { education, management, sociology, } \\
\text { and psychology. It provides an } \\
\text { important link in the application of } \\
\text { theory and research to HRD } \\
\text { practice. HRDQ publishes } \\
\text { scholarly work that addresses the } \\
\text { theoretical foundations of HRD, } \\
\text { HRD research, and evaluation of } \\
\text { HRD interventions and contexts. } \\
\text { Retrieved from: } \\
\text { http://onlinelibrary.wiley.com/jour } \\
\text { nal/10.1002/\%28ISSN\%291532- } \\
1096 / \text { homepage/ProductInformatio } \\
\text { n.html }\end{array}$ & 1990 & $\begin{array}{c}\text { Valerie Anderson } \\
\text { - Co Editor } \\
\text { Kim F. Nimon - } \\
\text { Co - Editor } \\
\text { Jon M. Werner - } \\
\text { Co Editor }\end{array}$ & $\begin{array}{c}\text { 2014 SSCI } \\
\text { Rating .833 } \\
2014 \\
\text { Rankings: } \\
13 / 27 \\
\text { Industrial } \\
\text { Relations \& } \\
\text { Labor } \\
50 / 76 \\
\text { Psychology } \\
\text { Applied; } \\
127 / 185 \\
\text { Management } \\
\\
\text { Editorials, } \\
\text { Empirical } \\
\text { Research } \\
\text { Articles, } \\
\text { Media } \\
\text { Reviews }\end{array}$ \\
\hline $\begin{array}{c}\text { Human } \\
\text { Resource } \\
\text { Developm } \\
\text { ent } \\
\text { Internatio } \\
\text { nal } \\
(\text { HRDI })\end{array}$ & $\begin{array}{l}\text { Human Resource Development } \\
\text { International promotes all aspects } \\
\text { of practice and research that } \\
\text { explore issues of individual, group } \\
\text { and organizational learning and } \\
\text { performance. Human Resource } \\
\text { Development International is } \\
\text { committed to questioning the } \\
\text { divide between practice and theory; } \\
\text { between the practitioner and the } \\
\text { academic; and between traditional } \\
\text { and experimental methodological } \\
\text { approaches. }\end{array}$ & 1998 & Carole Elliott & $\begin{array}{l}\text { International } \\
\text { Journal. } 1 \\
\text { Special Issue } \\
\text { per Volume }\end{array}$ \\
\hline $\begin{array}{l}\text { Advances } \\
\text { in }\end{array}$ & $\begin{array}{l}\text { Advances in Developing Human } \\
\text { Resources connects HRD research }\end{array}$ & 1999 & $\begin{array}{l}\text { Michael } \\
\text { Leimbach }\end{array}$ & $\begin{array}{l}\text { Thematic } \\
\text { journal }\end{array}$ \\
\hline
\end{tabular}




\section{Developing a Tradition of Scholarship}

\begin{tabular}{|c|c|c|c|c|}
\hline $\begin{array}{l}\text { Developin } \\
\text { g Human } \\
\text { Resources } \\
(\text { ADHR })\end{array}$ & $\begin{array}{l}\text { and theory to and from practice to } \\
\text { help scholar-practitioners work } \\
\text { effectively within the field. }\end{array}$ & & & $\begin{array}{l}\text { Emphasizing } \\
\text { implications } \\
\text { for HRD } \\
\text { practice. Each } \\
\text { issue has an } \\
\text { issue editor(s) }\end{array}$ \\
\hline $\begin{array}{c}\text { Human } \\
\text { Resource } \\
\text { Developm } \\
\text { ent } \\
\text { Review } \\
(\text { HRDR })\end{array}$ & $\begin{array}{l}\text { Human Resource Development } \\
\text { Review is a theory journal for } \\
\text { scholars of human resource } \\
\text { development and related } \\
\text { disciplines. The journal publishes } \\
\text { articles that make theoretical } \\
\text { contributions including theory } \\
\text { development, foundations of } H R D \text {, } \\
\text { theory building methods, and } \\
\text { integrative reviews of the literature. }\end{array}$ & 2002 & $\begin{array}{l}\text { Julia Storberg- } \\
\text { Walker }\end{array}$ & $\begin{array}{c}\text { 2014 SSCI } \\
\text { Rating } 1.366 \\
\text { Ranked } \\
80 / 185 \text { in } \\
\text { Management }\end{array}$ \\
\hline
\end{tabular}

\section{Human Resource Development Quarterly (HRDQ)}

The first issue of Human Resource Development Quarterly (HRDQ) appeared in Spring, 1990 with the official launch of the journal sponsored by the American Society for Training and Development (ASTD) and published by Jossey-Bass, Inc. The inaugural editorial team consisted of Editor Richard A. Swanson and Associate Editor Gary N. McLean, Managing Editor Sandra J. Johnson, and Statistical Consultant Douglas H. Anderson. The Editorial Board consisted of seven members: Roger D. Bennett, Michael A. Berger, Mary Anne Devanna, Eric G. Flamholz, David L. Passmore, Marshall Sashkin, and Edgar H. Schein.

The inaugural editorial described that "the embryonic home of $H R D Q$ was the research committee of the American Society for Training and Development (ASTD), and eventually a partnership evolved between the research committee, the Training and Development Research Center of the University of Minnesota, and Jossey-Bass Publishers” (Swanson, 1990, p. 2). In his opening editorial, Swanson reflected about the nature of experiences and acknowledged, 


\section{Developing a Tradition of Scholarship}

But here we are, the human resource development (HRD) profession, in a field of practice - experiences - that we are very proud of. Our years of experience alone have taken us about as far as we can go. Without seriously studying and reflecting on our profession and without developing sound theories to explain and challenge our practice, we will continue to repeat our experiences without learning from them. Currently, HRD personnel continue to rely on trial-and-error methods of managing, designing, delivering, and evaluating HRD efforts (pp. 1-2).

He acknowledged the HRD field had "not yet enjoyed the benefits of sound research or the cumulative power of research applied to everyday professional practice" (p. 2) and thus introduced $H R D Q$ as " $H R D Q$ to the rescue" (p. 2). Swanson indicated, that while it might be presumptuous to suggest that $H R D Q$ had come to the rescue, rather, "it is reasonable to declare that the scholarly readiness of the profession and the organizations in which it operates makes HRDQ possible" (p. 2).

Indeed, $H R D Q$ became a reality, and for many scholars, has been pivotal for the community of HRD scholars. As the first scholarly journal focused on the evolving field of HRD, $H R D Q$ has also evolved from its humble beginnings. Over the years, the sponsorship of the journal changed with both ASTD and AHRD sponsoring the journal, to sole sponsorship by the AHRD. The initial leadership structure of $H R D Q$ consisted of an editor and associate editor each serving 4 year terms with the associate editor transitioning into the editor role at the conclusion of the respective terms. Managing editors and statistical consultants have also changed with the editorial transitions, and new types of expertise, such as qualitative methods experts have contributed to the journal, along with additions to the editorial board which is now comprised of over 66 members. Throughout this time period, however, the aim and scope of the 


\section{Developing a Tradition of Scholarship}

journal has remained fairly steadfast as being "a central focus for research on HRD issues" and for disseminating such research. While $H R D Q$ is concerned with the practical implications of the research that it publishes, articles concerned solely with practice are not within the journal's purview.

In 2010, $H R D Q$ became indexed in Thomson Reuter's Social Science Citation Index (SSCI/ISI), which generates an annual report of the journal impact factor which reflects "an index of quality of scientific journals" (Falagas, Kouranos, Arencibia-Jorge and Karageorgopoulous (2008, p. 2623; Russ-Eft, 2008). Inclusion in SSCI has resulted in tremendous growth for the journal with over 200 submissions in 2012 alone. As a consequence of this growth in submissions, in 2013, a multi-associate editor platform was introduced, editorial terms were reduced to three years, and succession planning was refined (Ellinger, 2013, 2015). $H R D Q$ recently celebrated its $25^{\text {th }}$ Silver Anniversary in 2014. When the journal transitioned in 2016, a co-editor leadership structure was introduced to facilitate the distribution of a growing editorial workload and to enable the implementation of specific strategies developed for the journal's continued evolution. Table 2 presents the chronology of editors who have served the journal.

Table 2. Editor and Co-Editors for Human Resource Development Quarterly (HRDQ)

\begin{tabular}{|c|c|c|}
\hline HRDQ Editors & Journal Home & Years \\
\hline Richard A. Swanson, Editor & University of Minnesota & $1990-1993$, Volumes 1-4 \\
\hline Gary N. McLean, Editor & University of Minnesota & $1994-1997$, Volumes 5-8 \\
\hline Ronald L. Jacobs, Editor & The Ohio State University & $1998-2001$, Volumes 9-12 \\
\hline Darlene Russ-Eft, Editor & $\begin{array}{c}\text { American Institutes for } \\
\text { Research and Oregon State } \\
\text { University }\end{array}$ & $2002-2005$, Volumes 13-16 \\
\hline Timothy G. Hatcher, Editor & $\begin{array}{c}\text { North Carolina State } \\
\text { University }\end{array}$ & $2006-2009$, Volumes 17 - 20 \\
\hline
\end{tabular}




\section{Developing a Tradition of Scholarship}

\begin{tabular}{|c|c|c|}
\hline Baiyin Yang, Editor & Tsinghua University, China & $\begin{array}{c}2010-2013, \text { Volumes } 21- \\
24(2)\end{array}$ \\
\hline Andrea D. Ellinger, Editor & $\begin{array}{c}\text { The University of Texas at } \\
\text { Tyler }\end{array}$ & $\begin{array}{c}2013 \text { - 2016, Volumes 24(3) } \\
-27(1)\end{array}$ \\
\hline $\begin{array}{l}\text { Valerie Anderson, Co-Editor } \\
\text { Kim F. Nimon, Co-Editor } \\
\text { Jon M. Werner, Co-Editor }\end{array}$ & $\begin{array}{c}\text { University of Portsmouth, } \\
\text { UK } \\
\text { The University of Texas at } \\
\text { Tyler } \\
\text { University of Wisconsin- } \\
\text { Whitewater }\end{array}$ & $\begin{array}{c}2016-2019, \text { Volumes } 27(2) \\
-30(1)\end{array}$ \\
\hline
\end{tabular}

When $H R D Q$ began, the basic structure of each issue consisted of an editorial, a feature article and invited reaction to the featured article, refereed articles, a non-refereed Forum section, and a section for reviews of books, software and media. Refereed contributions undergo a blind peer-review process in which reviewers assigned to a submission do not know the identity of the author and the author does not know the identity of the reviewers. In contrast, non-refereed submissions typically do not undergo a blind peer-review process and may be reviewed by members of the editorial team. The content structure and review process associated with the journal has largely been maintained over the years, although, with page count budget constraints, and evolving needs of the research community, and the inception of other AHRD sponsored journals, the journal has endeavoured to focus more on refereed empirical contributions. It is anticipated that changes in the content structure of the journal will continue to evolve.

At its inception, $H R D Q$ published theoretical and conceptual articles, literature reviews, and empirical research. The conceptual boundaries of $H R D Q$ were initially depicted in a 2 X 2 matrix (Swanson, 1990). The vertical axis reflected inquiry methods (quantitative and qualitative) and the horizontal axis reflected two conceptual domains: human development and human capital, drawing from psychology and education, and economics and management, respectively. From this beginning, the conceptual boundaries of $H R D$ and $H R D Q$ have continued 


\section{Developing a Tradition of Scholarship}

to expand in terms of inquiry methods and content. Although the journal receives a large volume of quantitative studies, recent submissions show an increase in qualitative studies, and increased attention towards mixed designs. Further, the interdisciplinary nature of the HRD field continues to reflect variation in content beyond Swanson's initial conceptual dimensions.

In an analysis of the major topics addressed in $H R D Q$ from 2005 - 2014, Werner (Forthcoming) indicated that the greatest number of articles (and editorials) focused on defining HRD, theory building, establishing boundaries for HRD relative to other fields. He acknowledged that the next most studied topics included employee attitudes pertaining to HRD, career development, trainee motivation, teams, training transfer, organization development and change, diversity, leadership development, coaching, feedback, and trainee personality characteristics. Other articles reflected scale validations for HRD-relevant constructs, or focused on needs assessment, job competencies, training evaluation models, and trainee utility perceptions (pp. 16-17).

In the Silver Anniversary Volume 25, featured articles were solicited from leading scholars on a range of topics including ability, informal and incidental learning and the learning organization, HRD research and practitioner roles, national HRD, organization development and change, employee engagement, mix-method research design, talent management, future developments in training and power and emotions. These articles should stimulate and catalyze future research on compelling topics for the HRD field.

Although $H R D Q$ has undergone a variety of changes in its editorial structure over the years, and has experienced considerable growth in numbers of submissions received, many enhancements have been made to ensure that journal operations remain sustainable for the longer term future. Ensuring the long term viability of the journal is critical for the HRD field because, 


\section{Developing a Tradition of Scholarship}

from 2013 through the end of 2015, the editorial team processed over 700 submissions from 59 countries reflecting the global reach of $H R D Q$.

\section{Human Resource Development International (HRDI)}

According to Elliott, there are two narratives for situating the history and development of Human Resource Development International (HRDI). One is an institutional narrative that locates the emergence of $H R D I$ within a specific socio-historical context and describes how the journal emerged from the University Forum for HRD (UFHRD) and EURESFORM.

Discussions in UFHRD and EURESFORM about the need for a journal which adopted an international focus and welcomed a range of philosophical stances began in the mid-90's (Lee, 2002), not long after the 1994 merger of two UK professional bodies: the Institute of Personnel Management (IPM) and the Institute of Training and Development (ITD) to form the (then) Institute of Personnel and Development (IPD), now the Chartered Institute of Personnel and Development (CIPD). The journal's relationship with AHRD did not begin until 1997, when UFHRD “discovered” AHRD (Lee, 2002, p. vi). Viewed 20 years later, this period has attained pivotal status in the continuing development of the HRD field in the UK and Europe. It cemented HRDI's position as a core journal underpinned by a stance that views HRD theory and practice as "multifaceted, situated and complex" (Lee, 1998, p. 4).

Another narrative is a more personal one, not specifically to Elliott as current Editor-inChief, but to everyone who has either edited, acted as a reviewer, or published in the journal. Monica Lee, HRDI's first Editor-in-Chief, described her relationship with the journal in her final editorial in 2002 (Lee, 2002). This offered a rare glimpse into the affective and cognitive dimensions of the journal's foundation, and for which traces in the journal's aims and scope, which have remained solid since the first Volume, can be discerned. Core to these aims are the 


\section{Developing a Tradition of Scholarship}

commitment to question the divide between theory and practice and therefore between the practitioner and the academic. A driver for the journal's foundation was to remain open to a range of methodological approaches and theoretical stances, and so to offer a space for critical alternatives to the performance paradigm. Elliott's relationship to the journal can be related as a narrative of personal development, situated in an institutional context that has encouraged her development from the role as the journal's first managing editor to its current Editor-in-Chief.

Since the first volume was published in 1998, just in time for the AHRD conference of that year, the journal has developed from one that relied on rudimentary spreadsheets to manage the manuscript flow, to one where the entire manuscript production process is managed electronically. HRDI's editors-in-chief have moved from one side of the Atlantic Ocean to another, and have all played a distinguished role in the HRD field and the development of HRDI. The structure of the editorial board has shifted since the first volume when Gary McLean served as the first General Editor for North America, and Devi Jankowicz as General Editor for Europe. $H R D I$ - as reflection of its commitment to theory and practice - now has an associate editor for the peer reviewed section, and one for the Perspectives on Practice section. These early years were marked by the merging of the institutional and personal narratives when Monica Lee suffered a cerebral haemorrhage in the summer of 1998, and Devi Jankowicz stepped in to act as Editor-in-Chief. That the journal withstood such a blow in its formative years is testament to the goodwill and support of the editorial board, UFHRD, AHRD, and the wider community of HRD scholars.

In 2005, Jean Woodall (initially Kingston University, UK then Oxford Brookes University, UK) became Editor-in-Chief. One of the papers included in her first volume was written by Alexandre Ardichvili, who later served as Editor-in-Chief from 2013-2015. In 


\section{Developing a Tradition of Scholarship}

Woodall's final editorial (should include citation, Woodall, 2006), she articulated the style of leadership she sought to bring during her tenure, which was to "focus upon encouragement, support, exploration and even some risk taking rather than rigid adherence to specific position statements and views of the world" (2006, p. 443). Within this statement a commitment to HRDI's founding aims and scope can be seen along with a signal to scholars and practitioners to engage critically with HRD's role in theory and practice, a purpose enabled by the Perspectives on practices section of the journal, alongside the peer reviewed papers.

Peter Kuckinke, the University of Illinois, Urbana Champaign, became the first United States based Editor-in Chief, when he succeeded Jean Woodall in 2007, at the time of the journal's $10^{\text {th }}$ anniversary. In Kuchinke' s (2007) first editorial, he reminded readers that HRDI's success was due to its international focus and its rare status as a journal co-sponsored by two associations committed to developing the HRD field, that is UFHRD and AHRD. He noted, too, that given the increasing interconnectivity of organisations, global institutions, regions and countries, HRDI was well situated for growth and influence.

Rob Poell, Tilburg University in The Netherlands assumed the Editor-in-Chief role in 2010. Poell's first editorial described well the extensive and intricate nature of work performed by an editor-in chief; the type of work that generally remains hidden but which is crucial to the field's sustainability.

Alexandre Ardichvili, University of Minnesota, became the Editor-in-Chief for Volume 16 in 2013. Ardichvili had worked alongside Sally Sambrook and Rob Poell on the journal and, in his first editorial, described his personal relationship with HRDI and the role it had played in his career development. He had acted as an HRDI reviewer, author, and associate editor before becoming editor-in-chief. What had attracted him to $H R D I$ in the first place, he wrote, was its 


\section{Developing a Tradition of Scholarship}

culture, which he described as "a culture that encourages intellectual curiosity and exploration of new possibilities; is open to publishing articles based on a variety of methodological approaches to doing research and presenting results; recognizes that different cultures may have different views of what is scholarship and academic writing; welcomes diverse types of manuscripts based on various research approaches and paradigms; and adopts a broad definition of what HRD is" (p. 2). This is a culture that Elliott, HRDI's current Editor-in-Chief, alongside HRDI's associate editors: Jessica Li and Rajashi Ghosh, intend to maintain. Please refer to Table 3 for a chronological listing of editors.

Table 3. Editors of Human Resource Development International (HRDI)

\begin{tabular}{|c|c|c|}
\hline HRDI Editors & Journal Home & Years \\
\hline Monica M. Lee & Lancaster University & $1998-2002$ \\
\hline Jean Woodall & University of Kingston & $2003-2006$ \\
\hline K. Peter Kuchinke & $\begin{array}{c}\text { University of Illinois at } \\
\text { Urbana Champaign }\end{array}$ & $2007-2009$ \\
\hline Rob Poell & University of Tilburg & $2013-2015$ \\
\hline Alexandre Ardichvili & University of Minnesota & $2016-2018$ \\
\hline Carole Elliott & University of Roehampton & \\
\hline
\end{tabular}

\section{Advances in Developing Human Resources (ADHR)}

Advances in Developing Human Resources (ADHR) began publication in 1999 with the first issue focused on performance improvement. From its inception $A D H R$ has been a unique journal. Each issue is thematic, with scholars and/or scholar practitioners who have expertise on a particular topic serving as issue editors. The other unique quality of the journal is its emphasis on HRD practice. The preface of one issue indicated, "The mission . . . is to bridge research and 


\section{Developing a Tradition of Scholarship}

theory to and from practice in such a way as to help scholar-practitioners . . . to work more effectively in human resource development” (Lynham \& McDonald, 2011, p. 131).

Richard A. Swanson served as Editor-in-Chief (EIC) for the first four years the journal was published. During most of his tenure, Berrett-Koehler published the journal. Sage, the current publisher, took over in 2001. Swanson was also the only editor to serve a total of four years. After his term, three-year terms for editors were established and an Associate EIC position was created. Over the years $A D H R$ 's editorial board and team has expanded to more effectively accomplish the work of the journal and to broaden representation. Currently there are approximately fifty board members and four associate editors assisting the EIC. Please refer to Table 4 for a chronological listing of the journal's EICs.

Table 4. Editors-in-Chief for Advances in Developing Human Resources (ADHR)

\begin{tabular}{|c|c|c|}
\hline ADHR Editors & Journal Home & Years and Volumes \\
\hline Richard A. Swanson & University of Minnesota & $1999-2002$, Volumes 1-4 \\
\hline Scott D. Johnson & $\begin{array}{c}\text { University of Illinois at } \\
\text { Urbana-Champaign }\end{array}$ & $2003-2004$, Volumes 5-6 \\
\hline Wendy E.A. Ruona & University of Georgia & $2005-2007$, Volumes 7-9 \\
\hline Kenneth R. Bartlett & University of Minnesota & $2008-2009$, Volumes 10-11 \\
\hline Susan A. Lynham & Colorado State University & $2009-2012$, Volumes 12-14 \\
\hline Kimberly S. McDonald & $\begin{array}{c}\text { Indiana University-Purdue } \\
\text { University Fort Wayne }\end{array}$ & $2012-2015$, Volumes 15-17 \\
\hline Michael P. Leimbach & Wilson Learning Worldwide & $2015-2018$, Volumes 18-20 \\
\hline
\end{tabular}

*For several years the change in EIC occurred at the beginning of the calendar year. Now the change-over in EICs occurs on July 1. Most of the editorial work for that year's volume has been completed by the time of the transition. 


\section{Developing a Tradition of Scholarship}

$A D H R$ 's early issues tended to focus on performance and learning, core topics for the discipline. However within a short period of time, authors looked to $A D H R$ as an outlet for writing about innovative topics and using varied approaches to examine issues relevant to HRD. For example, in 2001, an issue on "Metaphor in HRD" was published. Also appearing that year was an issue devoted to short cases based on the AHRD Standards on Ethics and Integrity. Both of these are examples of topics and approaches that are of interest and of use to the HRD community, but would not necessarily fit the editorial guidelines or the mission of other HRD journals. $A D H R$ is typically the outlet academics turn to when they want to discuss and write about HRD educational programs and curriculum. Some examples include issues on the use of popular culture in leadership education and development, diversity education, and a recent issue looking at the scholarship of teaching and learning from an international perspective.

$A D H R$ issues have been used by professors and practitioners as texts for courses and/or workshops. Swanson (2000) encouraged readers to consider using ADHR for this purpose and provided examples of how the first few issues were being used as supplementary texts at the University of Minnesota. Current practice suggests that entire issues are less likely to be used in HRD classes, however on-line usage statistics would indicate that students in HRD-related classes continue to use specific articles for coursework.

A variety of topics have been the focus of $A D H R$ issues. Often they address current problems and issues facing HRD in various contexts (e.g., "HRD's role in addressing Workplace Incivility \& Violence"), some focus on developmental activities commonly used in organizations to improve performance and enhance learning (e.g., "Coaching and HRD”), while others explore ways to improve our research and theory-building skills (e.g., "Theory building in applied disciplines," and "Quantitative data-analytic techniques to advance HRD theory and practice"). 


\section{Developing a Tradition of Scholarship}

Throughout the years there have been multiple issues addressing topics such as technology and HRD, leadership development, and workforce diversity. Occasionally topics have been revisited - usually with the same individuals serving as issue editors. For example, ten years after their first issue on the Dimensions of the Learning Organization Questionnaire (DLOQ@), Watkins, Marsick, and Dirani (2013) revisited the DLOQ@ in an issue that examined what is known about organizational learning after a decade of research findings using the DLOQ( and lessons learned about using the instrument in a variety of international contexts.

While issue topics have evolved since the journal's inception, at its core $A D H R$ strives to advance the practice of HRD. On the surface this core focus appears straight forward. But ensuring that HRD practice is advanced in a rigorous and relevant manner requires a publication that emphasizes practice with a strong grounding in theory and research. This balance between rigor and relevance poses some challenges to $A D H R$ stakeholders. For example, securing SSCI ranking is difficult for a thematic journal written for a scholar-practitioner audience. Yet, its uniqueness is also a strength in that $A D H R$ can address the needs of HRD professionals, students, and scholars by being a platform for emerging topics and/or methodologies that can improve the practice of developing individuals in various contexts.

\section{Human Resource Development Review (HRDR)}

In March 2000, a phone call between AHRD leaders and Sage Publications representatives started the process of creating a theory journal for the field (Holton III, 2002a). After two years of preparation and focused efforts, the journal first appeared, and Human Resource Development Review (HRDR) became a reality. Since that time HRDR has had six academic homes, five editors, and has published 14 volumes. Most notably, Thomson-Reuters 


\section{Developing a Tradition of Scholarship}

selected $H R D R$ for coverage in the SSCI, and the journal received its impact factor of 1.366 in the spring of 2015. HRDR is currently ranked 80 out of 185 journals in the highly competitive management category.

$H R D R$ 's success has everything to do with the people who support the journal in a variety of capacities, and over the years the journal's editors, associate editors, managing editors, and editorial boards have worked diligently to publish articles of meaning, relevance, and impact for the field. Storberg-Walker is the journal's fifth editor, and she follows the exemplary contributions of Drs. Jamie Callahan, Thomas Reio, Richard Torraco, and Elwood Holton III. $H R D R$ is currently hosted by George Washington University; prior academic homes include Drexel, Texas A\&M, Florida International University, the University of Nebraska-Lincoln, and Louisiana State University. The support of these Universities has also contributed to the journal's ability to contribute, and it is important to acknowledge the wide network — the 'village' — that it takes to run a journal. Please refer to Table 5 for a chronological listing of editors.

Table 5. Editors of Human Resource Development Review (HRDR)

\begin{tabular}{|c|c|c|}
\hline HRDR Editors & Journal Home & Years \\
\hline Elwood Holton III & Louisiana State University & $2002-2005$ \\
\hline Richard Torraco & $\begin{array}{c}\text { University of Nebraska- } \\
\text { Lincoln }\end{array}$ & $2005-2008$ \\
\hline Thomas Reio & $\begin{array}{c}\text { Florida International } \\
\text { University }\end{array}$ & $2008-2011$ \\
\hline Jamie Callahan & $\begin{array}{c}\text { Texas A\&M, Drexel } \\
\text { University }\end{array}$ & $2014-2017$ \\
\hline Julia Storberg-Walker & $\begin{array}{c}\text { George Washington } \\
\text { University }\end{array}$ & \\
\hline
\end{tabular}




\section{Developing a Tradition of Scholarship}

At the beginning several recognized scholars championed the mandate for more theory in HRD. The 1990s were a vibrant time of growth for the AHRD and HRD, and by the turn of the century HRD's three journals $(H R D Q, H R D I, \& A D H R)$ were building new knowledge about HRD research and practice. The HRD narrative at that time was that $H R D Q$ published empirical research, $H R D I$ published articles of international interest, and $A D H R$ was the venue for connecting HRD research to practice. $H R D R$ aimed to fill a perceived gap in the knowledge base of HRD, much like the Academy of Management Review (now publishing its $41^{\text {st }}$ volume) filled the conceptual gap left by the empirically focused Academy of Management Journal (now in its $58^{\text {th }}$ year).

The initial focus of $H R D R$ has changed little over the years, as a review of the journal's first editorial makes clear:

The goals for $H R D R$ are not modest. They are as follows:

1. To promote theory and theory building in human resource development (HRD) and related fields.

2. To be the premier publication outlet for theory, theory-building research methods, and foundations in HRD.

3. To serve as a forum and catalyst for learning about good theory and theory building (Holton III, 2002a, p. 3).

The mission of HRDR - to be the catalyst for more robust theory in HRD — is accomplished by publishing four types of articles: a) theory development and conceptual articles; b) theorybuilding research method articles; c) foundations of HRD articles; and d) integrative reviews of literature. In addition, other sections of the journal were created and include the Instructor's 


\section{Developing a Tradition of Scholarship}

Corner (refereed and non-refereed) as well as Debate and Dialogue (non-refereed). The Debate and Dialogue section was intended to "provoke new theory or advances in theory" as "rather short opinion pieces that focus on critical issues in the field" (Holton III, 2002b, p. 144).

The first few years of editorials and articles in $H R D R$ mirror the intellectual foment of the time. First was the justification for a theory-based journal on what Burrell and Morgan (1979) would call a functionalist paradigm (e.g., Dubin (1969), Cohen (1989), and Kaplan (1964). The second year brought a call for "courage and heretical thinking" to break "the normal cycle of science" (Holton III, 2003, p. 5) as described by Kuhn (1996) to catalyze paradigm shifts in HRD. The third year the journal added two new types of articles to its list-meta-analyses focused on theoretical development; and non-refereed emerging ideas that "offer promise to spur additional theory building" (Holton III, 2004, p. 100). Richard Torraco assumed the role of Editor with the March, 2005 issue, and notably made a call for multiple perspectives: "provocative and persuasive theory that can change how we view our work and the phenomena central to our research and practice arises from diverse sources" (Torraco, 2005, p. 5-6).

Over the years, the journal maintained its focus on theory, theory building, and conceptual development. Editorials highlighted new and emerging focal areas for HRD, including complexity (Yorks \& Nicolaides, 2006); policy and practice (Smith, 2006); low-skilled workers (Torraco, 2007); critical reflection (van Woerkom, 2008); and a challenge to technical rationality (Dirkx, 2008). A noteworthy scholarly exchange was published in the June, 2007 issue. Authors Peter Kuchinke, Gary May, and Jeff Bowman presented different perspectives on HRD practice, research, and education. The sentiments expressed by these authors are as relevant today as they were in 2007. In the exchange, $H R D R$ dedicated valuable publication space to exposing the various assumptions, intellectual currents, and epistemologies within the field of 


\section{Developing a Tradition of Scholarship}

HRD. Readers were provided with diverse representations of HRD and challenged to evaluate their own paradigm or belief system.

$H R D R$ has provided its readers with new knowledge through its peer-reviewed sections and has also increased the diversity of ideas and research capacity of its readers. For example, while $H R D R$ continued to publish conceptual and theoretical articles, there was a continual call by editors for more theory building research articles. Sensing that one reason for the lack of theory building submissions may be due to a lack of theory building skills, Reio (2010) offered detailed suggestions for developing theory building method skills and called for experienced theorists to submit 'how-to' articles to the Instructor's Corner section. In that same issue, Callahan (2010) provided readers with a clear description of integrative literature reviews and how they are different from theory and conceptual articles. With these publications and others like them, HRDR was not only contributing to HRD field through new knowledge; it was also assuming responsibility to help HRD scholars develop new research and writing skills.

At the present time, $H R D R$ is attracting more submissions than ever before, with a $41.5 \%$ increase since obtaining SSCI rating. More international authors are viewing $H R D R$ as a viable publication outlet, and $H R D R$ continues to produce volumes that inform, shape, inspire, and teach. While HRDR may have begun with a phone call in 2002, its sustained commitment to building new knowledge in and for HRD is clear, and it continues to publish manuscripts from diverse conceptual and theoretical perspectives. $H R D R$ has evolved over time but the original intent remains to catalyze new thinking and to present good theory. 


\section{Developing a Tradition of Scholarship}

\section{Insights Gleaned From Across the Four Journals}

The creation and launch of the four AHRD sponsored journals have provided publishing venues for HRD scholars and practitioners that accommodate a wide range of topics, types of articles, and diverse research methods to enable the dissemination of research for the field of HRD. The published content of these journals presents a rich history of HRD scholarship that can be further analysed. Ghosh, Kim, Kim and Callahan (2014) have acknowledged that several scholars have published articles that have "attempted to capture a glimpse of this dynamic nature of the field in different ways" (p. 303). For example, Jo, Jeung, Park, and Yoon (2009) conducted the first citation network analysis among the four AHRD journals from 1990 -2007. They found that learning and performance in HRD, theory building in HRD, and training (or learning) transfer were important themes. In 2011, Jeung, Yoon, Park, and Jo conducted a citation and content analysis and identified the top 20 journal articles across the four AHRD journals that had been most frequently cited in other non-AHRD academic journals. Their findings suggested that training transfer and evaluation, learning in organizations, and knowledge sharing and knowledge creation were the three key research themes.

Despite these and other studies, Ghosh et al. (2014) acknowledged that what has been lacking is a "content analysis of HRD scholarship" (p. 303) by examining the four scholarly journals in the field. To address one of their research questions, which focused on a frequency analysis of peer-reviewed articles published from 2002-2011 across the four AHRD sponsored journals, they identified 42 themes and then the top 10 themes among them which included: learning, training, leadership, NHRD, culture, performance, work attitude, diversity, career and knowledge. They also examined waning, steady, and emerging themes in HRD research as well as the distinct aims and scope of the journals, and editorial discretion. As can be seen from these 


\section{Developing a Tradition of Scholarship}

research studies, there is some consistency in overall content themes across the four journals. However, as Ghosh et al. suggest, there are several pathways for expanding research that examines the content of HRD focused journals beyond those sponsored by the AHRD.

In summary, this article has endeavoured to provide a history of the emergence and evolution of the AHRD sponsored journals and the contributions that these journals have made to the HRD field in terms of their aims and scope, their editorial leadership, and ultimately the scholarship they have published. In addition to the empirical research, conceptual articles, literature reviews, and theoretical contributions, many of these journals have also been committed to influencing the practice of teaching, research, and building reviewer capacity through the articles that have been written to assist researchers, practitioners, and students with "how to guides" that improve writing, research, and reviewer skills. A hallmark of many of these journals is the requirement to acknowledge how the scholarship may be useful in practice.

While the HRD field will continue to evolve, it is certain that the journals will also continue to evolve as research standards and issues associated with rigor and robustness change and demands increase for HRD researchers to "engage in translational research or research that supports evidence-based management" (Nimon \& Astakhova, 2015, p. 231). For example, the editorial by Gubbins and Rousseau (2015) introduced translational research and presented a number of recommendations to HRD researchers for increasing the impact of their research. In addition, the editorial by Nimon and Astakhova (2015) articulated a number of recommendations for increasing the rigor of quantitative HRD research. Equally important, however, is that researchers and practitioners will likely be challenged to continue to examine topics that are relevant, meaningful, and impactful to the HRD field and other HRD-related disciplines. 


\section{Developing a Tradition of Scholarship}

\section{References}

Bowman, J.S. (2007). Invited reaction: Protecting the birds' feathers - keeping ideology out of MBA and HRD programs. Human Resource Development Review, 6(1), 132-135.

Burrell, G. \& Morgan, G. (1979). Sociological paradigms and organizational analysis: Elements of the sociology of corporate life. Burlington, VT: Ashgate.

Cohen, B.P. (1989). Developing sociological knowledge: Theory and method. Chicago: NelsonHall.

Dirkx, J. (2008). The epistemology of practice: An argument for practice-based research in HRD. Human Resource Development Review, 7(3), 263-269.

Dubin, R. (1969). Theory building: A practical guide to the construction and testing of theoretical models. New York: Free Press.

Ellinger, A. D. (2013). It takes a global community of scholars to sustain a journal. Human Resource Development Quarterly, 24(3), 277-283.

Ellinger, A. D. (2015). Moving on and moving upward: Final reflections and farewell. Human Resource Development Quarterly, 27(1), 9-12.

Ghosh, R., Kim, M., Kim, S., \& Callahan, J. L. (2014). Examining the dominant, emerging, and waning themes featured in select HRD publications: Is it time to redefine HRD? European Journal of Training and Development, 38(4), 302-322. 


\section{Developing a Tradition of Scholarship}

Gubbins, C., \& Rousseau, D. M. (2015). Embracing translational HRD research for evidencebased management: Let's talk about how to bridge the research-practice gap. Human Resource Development Quarterly, 26(2), 109-125.

Holton III, E.F. (2002a). The mandate for theory in HRD. Human Resource Development Review, 1(1), 3-8.

Holton III, E.F. (2002b). The theory and research we take for granted. Human Resource Development Review, 1(2), 143-144.

Holton III, E.F. (2003). Beyond incrementalism? What's the next paradigm for HRD? Human Resource Development Review, 2(1), 3-5.

Holton III, E.F. (2004). Welcoming meta-analysis and emerging ideas to HRDR. Human Resource Development Review, 3(2), 99-101.

Kaplan, A. (1964). The conduct of inquiry: Methodology for behavioral science. New Brunswick, NJ: Transaction.

Kuchinke, K. P. (2007). HRDI at ten! Human Resource Development International, 10(1), 1-4.

Kuchinke, K. P. (2007). Birds of a feather? The critique of the North American business school and its implications for educating HRD practitioners. Human Resource Development Review, 6(1), 111-126.

Kuchinke, K.P. (2007). Response to May and Bowman: HRD-multiparadigmatic, multidisciplinary, open-ended, and complex. Human Resource Development Review, $6(1), 136-141$. 


\section{Developing a Tradition of Scholarship}

Kuhn, T.S. (1996). The structure of scientific revolutions $\left(3^{\text {rd }}\right.$ ed). Chicago: University of Chicago Press.

Lee, M. (1998). Editorial. HRDI: A journal to define. Human Resource Development International, 1(4), 1-6.

Lee, M. (2002). Editorial. To say goodbye. Human Resource Development International, 5(4), pp. iii-viii.

Lynham, S. A. \& McDonald, K.S. (2011). There's nothing quite as practical as good research. Advances in Developing Human Resources, 13, 131-134.

May, G.L. (2007). Invited reaction: Birds of a feather? HRD and business schools should flock together. Human Resource Development Review, 6(1), 127-131.

Nimon, K. F., \& Astakhova, M. (2015). Improving the rigor of quantitative HRD research: Four recommendations in support of the general hierarchy of evidence. Human Resource Development Quarterly, 26(3), 231-247.

Reio, T. (2010). The ongoing quest for theory-building research methods articles. Human Resource Development Review 9(3), 223-225.

Russ-Eft, D. (2008). SSCI, ISI, JCR, JIF, and journal quality. Human Resource Development Quarterly, 19(3), 185-189.

Smith, A. (2006). Engagement or irrelevance? HRD and the world of policy and practice. Human Resource Development Review, 5(4), 395-399.

Swanson, R. A. (1990). Experience: A questionable teacher. Human Resource Development Quarterly, 1(1), 1-4. 


\section{Developing a Tradition of Scholarship}

Swanson, R.A. (2000). Using Advances in Developing Human Resources as a text. Advances in Developing Human Resources, 2, 117.

Swanson, R. A. (2009). Human Resource Development Quarterly: In the beginning. Human Resource Development Quarterly, 20(1), 3-5.

Torraco, R. (2005). Ratings, rankings, results, and what really matters. Human Resource Development Review, 4(1), p. 3-7.

Torraco, R. (2007). Low-skilled adults in the United States: A case of HRD underdevelopment. Human Resource Development Review, 6(4), 343-352.

Van Woerkom, M. (2008). Critical reflection and related higher-level conceptualizations of learning: Realistic or unrealistic? Human Resource Development Review, 7(1), 3-12.

Watkins, K.E., Marsick, V.J. \& Dirani, K.M. (2013). Making learning count: Diagnosing the learning culture in organizations, second edition. Advances in Developing Human Resources, 15.

Werner, J. M. (Forthcoming). Training from the perspective of human resource development and industrial and organizational psychology: Common past, parallel paths - Going where? In K.G. Brown (Ed.) Cambridge handbook of workplace training and employee development. Cambridge University Press.

Yorks, L, \& Nicolaides, A. (2006). Complexity and emergent communicative learning: An opportunity for HRD scholarship. Human Resource Development Review, 5(2), 143-147. 


\section{Developing a Tradition of Scholarship}

\section{Author Biographies:}

Andrea D. Ellinger, PHR, is a Professor in the Department of Human Resource Development in the College of Business and Technology at The University of Texas at Tyler. She recently completed her editorship of Human Resource Development Quarterly. Andrea has received numerous awards in recognition of her teaching, research, and service, most notably the Outstanding HRD Scholar Award for 2012 presented by the Academy of Human Resource Development. Her research on informal learning in the workplace, organizational learning, evolving managerial roles, managerial coaching, mentoring, employee engagement, and the learning organization concept have appeared in numerous ranked journals. Andrea is a member of the Editorial Boards of the International Journal of Evidence Based Coaching and Mentoring, the Journal of Workplace Learning, Human Resource Development Quarterly, and Management Learning. She serves as a Consulting Editor for Adult Education Quarterly.

Carole J. Elliott is Professor of Human Resource Development at the University of Roehampton Business School in London, U.K., and visiting fellow at George Washington University, Washington, DC. She is editor-in-chief of the Taylor and Francis journal Human Resource Development International and Principal Investigator for the Economic and Social Research Council (ESRC) Seminar Series "Challenging Gendered Media (Mis)representations of Women Professionals and Leaders." Carole's principal research interests are in management and leadership learning, with a primary focus on the critical examination of women's leadership and women's leadership learning. Carole is a member of the International Leadership Association, European Group for Organizational Studies, the British Academy of Management, is an academic member of the Chartered Institute of Personnel and Development, and is a Fellow of the Leadership Trust Foundation in the U.K.

Kimberly S. McDonald is Professor of Organizational Leadership and Supervision and Associate Dean for the College of Engineering, Technology, and Computer Science at Indiana-Purdue University Fort Wayne. She recently completed her term as Editor-in-Chief for Advances in Developing Human Resources. She has published a variety of book chapters and journal articles, most of which focus on career development. Her co-authored book with Linda Hite, Career Development: A Human Resource Development Perspective, was recently published by Routledge.

Julia Storberg-Walker is an Associate Professor at George Washington University teaching in the Executive Leadership Program. She currently serves as the Editor of Human Resource Development Review, and is affiliated with the Taos Institute as well as the Global Women's Institute at GW. Her research interests focus on theorizing leadership for women and girls, and she has delivered theorizing workshops around the world for students and faculty. Most recently, she was recognized for her scholarly contributions by the Women and Leadership Affinity Group of the International Leadership Association and was awarded with the 2015 Outstanding Scholar Award. 